\title{
The Effects of the Social Context on Pre-Decisional Processes of Protective Action in Beijing Communities
}

\author{
Tiezhong Liu, Hubo Zhang, Xiaowei Li, Huiru Li \\ School of Management and Economics, Beijing Institute of Technology, Beijing 100081, China
}

Received 13 February 2016

Accepted 1 March 2016

\begin{abstract}
This paper examined the effects of the social context (media communication, face-to-face communication, and friend and kinship network) on pre decisional processes of individual protective action. A two-stage survey was carried out aimed at residents in Beijing communities in half a year, and then the data were disposed from three aspects: Common Method Variance, non-parametric test, and Exploratory Factor Analysis. Based on the pretest data $(\mathrm{N}=344)$ and the posttest data $(\mathrm{N}=351)$, analyses were implemented from aspects of competing model analysis, hypothesis path test, and Multiple Group Analysis with the method of Structural Equation Modeling. Results: First, media communication activities can influence individual reception of risk information, which influence is the strongest among social context variables; moreover education attainment and age can influence it significantly. Then media channel should be diverse with respect to the different groups in order to increase the degree of information reception. Second, face-to-face communication activities can influence individual attention behavior; at the same time, it can also influence media communication; in addition, education attainment and income level are can influence it significantly. Then physical activities should be specific with respect to different socioeconomic strata in order to raise the degree of information attention. Third, friendly and kinship network does not influence any pre decisional processes variable, but it can influence face-to-face communication instead. Then it can be seen that the role of social conformity should be emphasized in order to enhance the degree of individual participation. Fourth, no social context variable can exert significant influence on comprehension behavior. Then it can be seen that the literal problem should be emphasized in order to improve the degree of understanding of risk communication. Future research should cover the particular social context as regards demographic characteristics, the facilitating and barriers inside risk information, and the relationship between social conformity and risk communication.
\end{abstract}

Keywords: risk communication; health behavior; social influence; community involvement; demographic characteristics

\section{Introduction}

People usually acquire environmental risk information from direct observation or indirect perception. When the physical environment is complex or rapidly changing and supplies only subtle cues for predicting threats to people and property, physical reality testing tends to give way to social reality testing (Lindell and Perry, 2004, p.27). For example, although the public might not really understand complex technology, a series of environmental problems have become the hot topics of China, such as PX factories and inland nuclear power plants as a result of widespread media coverage (Zhu, 2014). In addition, disaster cues, such as earthquake cannot even predict by scientists, let alone lay people. Local people and organizations are always the main actors in disaster risk reduction activities (Maskrey, 1989). Therefore, since the public usually lacks direct ability to perceive hazard from their physical environment, it is important to discuss the role of social context on individual behavior.

In theory, such topics belong to the field of risk communication (Health \& O'Hair, 2009) and health behavior theory (Hayden, 2009). Based on previous theories (such as Shannon, 1948; Lasswell, 1948), Lindell and Perry $(2004,2012)$ have developed a 
Protective Action Decision Model (PADM) to describe the information source and individual protection action. In which they state that: risk information initiates a series of pre decisional processes, elicits core perceptions, and then motivates protective actions ( $p$. 48). It can be seen that pre decisional processes acts as the mediator between the social context and individual protection action. Although the primary focus of the PADM is on decision-making processes that take place in conscious awareness (Lindell and Perry, p.48), but the relationship between the social context and pre decisional processes has not been explained in detail, as well as later studies about the application of the PADM, such as Terpstra and Lindel (2012) and Wang (2014).

Thus, this paper contributes to the discussion about the effects of social context on pre decisional processes. The focus will be put on three aspects: to begin with, we will discuss the interactions between different social context variables; furthermore, we will discuss the specific relationships between social cues (such as friends, kinships, media) and individual psychological processes before decision-making; finally, we will discuss the variance of significant paths across demographic groups in order to clarify the circumstance of given connections. The discussion will be useful for perfecting the theory of PADM; at the same time, the clarification of social context will be helpful for advancing the coverage and effectiveness of risk communication.

\section{Methodology}

\subsection{Variables}

\subsubsection{Independent variables}

Social context variables were designated as independent variables. The PADM offers two kinds of social context in long-term hazard adjustment: friend and kinship networks and community networks (Lindell $\&$ Perry, 2004, p.139). Since the social context plays the sources of risk information, community networks can be represented by individual preference of the communication channel in the community. In view of risk communication activities in Chinese community, media style (such as TV, Radio, and newspaper) and physical activities (such as class, poster and emergency exercise), three social context variables were designed as follows.

First, media communication (MC).Media is the common channel for residents to acquire risk information, which are controlled by central and municipal government. Receiving information from media is self-driven behavior, so the influence of media communication can be seen as intrinsic motivation (Lazarus \&Folkman, 1984). This path is the same with the central route of Elaboration Likelihood Model (ELM), in which individual attention behavior is influenced more by the cognitive contents of the message (Petty \& Cacioppo, 1986). Therefore MC was designed to be measured by residents' attitude toward different media channel.

Second, face-to-face communication (FFC). There are many activities related to risk communication in Chinese community. Generally, the participation of these activities depends on compulsory or incentive factors, which reflects individual compliance with the authority or power (Lazarus\& Folkman, 1984). This path is the same with the peripheral route of ELM, in which individual attention behavior is influenced more by superficial cues available in the persuasive context (Petty \& Cacioppo, 1986). Therefore FFC was designed to be measured by residents' attitude toward different community activities.

Third, friend and kinship network (FKN). According to Wirth (1938)'s theory, complex social function creates unique personal interaction in mega city, which depending on specific identity status (occupation or role) instead of personality (emotion).Previous studies also confirmed this phenomenon in Beijing (Zhang, 2006). Therefore, FKN was designed to be measured with formal circles, such as community circles, working circles, and political circles.

\subsubsection{Dependent variables}

Predecisional processes variables were taken as dependent variables. Predecisional processes comprise three factors, which are reception of, attention to, and comprehension of socially transmitted information (Fiske \& Taylor, 1991). Then following variables were designed.

First, reception (RP).The reception means people's ability to receive information from external environment. It was measured with the individual access to the disaster information (such as rainfall, earthquake, and fire disaster)because information reception would depend on the invasion of normal activities (Lindell \& Perry 2004, p.76).

Second, attention (AT).The attention means people's ability to accept the cues, which depend on the expectations of threat, competing demands, and intrusiveness of hazard information (Lindell, 2004, p.49). It was measured with individual interest in different disaster information. 
Third, comprehension (CP).Generally, the comprehension refers to one's ability to understand the meaning, nature, or importance of something correctly. It was measured with a series of true or false questions related to protective knowledge of specific disaster types.

\subsubsection{Moderator variables}

It is well-documented that demographic characteristics can influence protective action, such as Enarson, Fothergill and Peek (2007)'s discussion about gender and disaster, Gaillard (2012)'s argument about Caste, ethnicity, religious affiliation and disaster. In view of the characteristics of residents in Beijing, six demographic variables were selected as moderator variables, including marital status, gender, age, ethnicity, education attainment, and income level.

In sum, we acquired twelve variables, including three independent variables (social context), three dependent variables (predecisional processes), and six moderator variables (demography). Their definition and measuring items are represented in Table 1.

Table 1. Definition of twelve variables

\begin{tabular}{llll}
\hline Type & Variables name & Symbol & Measuring items \\
\hline $\begin{array}{lll}\text { Demographic variables } \\
\text { (Moderator) }\end{array}$ & Marital status & $M R / U M$ & Married or Unmarried \\
& Gender & $M E / F M$ & Male or Female \\
& Age & $M D / Y U$ & Middle-aged (45-59) or Youth (18-44) \\
& Ethnicity & $M J / M N$ & Majority group (Han) or Minority group \\
& Education attainment & $H E / L E$ & Higher level (with Bachelor degree) or \\
& & & Lower level (without Bachelor degree) \\
& Income level & $H I / L I$ & Higher level (\$5,000.00-\$13,000.00) or \\
Social context variables & Media communication & $M C$ & Lower level (0-\$5,000.00) \\
(Independent) & Face-to-face communication & $F F C$ & Attitude toward media activities \\
& Friend and Kinship Network & $F K N$ & Personal social circles \\
Predecisional processes & Reception & $R P$ & Concern of the disaster information \\
variables (Dependent) & Attention & $A T$ & Interest of the disaster information \\
& Comprehension & $C P$ & True or false questions of disaster knowledge \\
\hline
\end{tabular}

\subsection{Hypothesis and Flow chart}

\subsubsection{Hypothesis}

Based on the PADM and previous analyses, the relationship between the social context and predecisional processes was focused in this paper. Then the hypothesis was stated as "if the social context was taken as information source, it would influence predecisional processes in different ways". It can be divided into three parts:

First, suppose MC would influence RP (H1a), $\mathrm{AT}(\mathrm{H} 1 \mathrm{~b})$, and $\mathrm{CP}(\mathrm{H} 1 \mathrm{c})$;

Second, suppose FFC would influence RP (H2a), AT (H2b), and $\mathrm{CP}(\mathrm{H} 2 \mathrm{c})$;

Third, suppose FKN would influence RP (H3a), AT (H3b), and CP (H3c).

\subsubsection{Flow chart}

In order to describe the relationships between different variables, a flow chart was designed with respect to above hypotheses and previous theories, as is shown in Figure 1.

First part presents the interactions between social context variables (FKN, FFT, MC). The PADM can't include these links, so they should be redesigned. Because friend and kinship network is relatively stable, we let FKN influence both FFC and MC; then we let FFC influence MCor let MC influence FFT. After a series of combination of "FKN, FFT, and MC", sixteen competing models can be obtained, which are show in Table 2. In which, the best fit model should represent the best combination of social context variables(Byrne, 2001). 


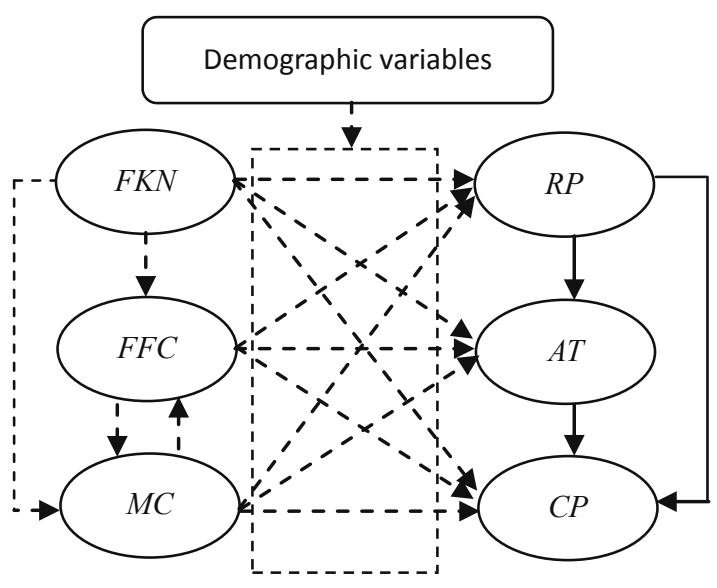

Figure 1. Flow chart about relationships between different variables

Second part presents the relationships between three predecisional processes (RP, AT, CP). In learning theories, constructivism emphasizes the importance of the background knowledge, which believes that when new information is approached, the learner faces a loss of equilibrium with their previous understanding, and then an improved cognitive schema can be formed (Bodner, Klobuchar, \&Geelan, 2001). Then it can be seen that the order of three predecisional processes should be "from reception (RP) to attention (AT)", and "from attention (AT) to comprehension (CP)" in the disaster schema.

Third part presents the specific effects between two types of variables. According to above hypothesis (section 2.2.1), we supposed every social context variables (FKN, FFT,MC) can influence every predecisional processes variables (RP, AT, CP). Then we acquired nine hypothesis paths, which should be tested later, as is shown in Figure 1.

Fourth part presents the role of specific demographic variable. For example, aimed at gender variable, we separated the sample into male group and female group, and then check the variance of particular relationship across groups.

\subsection{Data collection}

\subsubsection{Sampling}

The subjects are designed as residents in the Haidian District in Beijing. The population in Beijing is representative because $62 \%$ of them are registered residents, and $38 \%$ of them are non-registered residents, which come from all over the China. Furthermore, Haidian District is a typical district because it locates at the edge of Beijing, and its territory includes both urban communities and rural communities(BMBS, 2014).
Then sampling was implemented with stratified sampling technique (Cochran, 1977). First, community stratum: concerning the community category (CSSB, 2015), four types of communities were selected: new community (building before 1999), old community (building after 2000), rural community, and employer-governance community. Second, resident stratum: minimum sample size was calculated by the statistics equation of " $(\mathrm{Z} \text {-score })^{2} * \operatorname{StdDev}^{*}(1-\mathrm{StdDev}) /$ (Margin of Error)" (Smith, 2013), and then a threshold of 384 was found.

Meanwhile, taking into account the problem of method bias, a two-stage survey was carried out with half a year's interval: the pretest survey was implemented in September 2013, and the posttest survey was implemented in January 2014.

Finally, each respondent was given $\$ 5$ gift as an incentive of completing the questionnaire.

\subsubsection{Questionnaire}

Data were collected with method of the questionnaire survey. The questionnaire was designed concerning the definition of twelve variables. The draft was modified through the primary test and with the method of brainstorming. Then a questionnaire with five parts and 63 items was obtained: Part I is basic information of residents, which include personal information and social circle information, therefore it was used to measure demographic variables and variables of "FKN"; Part II was designed to measure variables of "RP" with a series of questions of "did you notice the following disaster information"; Part III was designed to measure variables of "AT" with a series of questions of "did you interest in the following disaster information"; Part IV was designed as to measure variables of "CP" with a series of true or false questions about disaster preparedness knowledge; Part $\mathrm{V}$ was designed to measure variables of "FFC" and "MC" with questions of "how about your attitude of the following risk communication activities".

\subsection{Data analysis}

\subsubsection{Primary analysis and Missing data}

Data were analyzed to check the reliability and validity with SPSS 20.0, and then following values were found: Cronbach's $\alpha$ is 0.867 for the pretest, 0.886 for the posttest; the parameter of KMO is 0.861 (sig. $=0.000$ ) for the pretest, 0.894 (sig. $=0.000)$ for the posttest, which show that the data are both reliable and valid.

The missing data were approached with two methods (Bouza-Herrera, 2010): to begin with, the samples with 
overmuch missing data (exceeding 30\% information) were deleted directly; furthermore, the method of hot-deck imputation was used to fill up the blank cells with the median value considering that those in the risk area are likely to engender protective actions by observing the behavior of others (Lindell\& Perry, p.55).

Then the final data were composed of 344 acceptable pretest samples, and 351 acceptable posttest samples. Demographic distribution are as follows: (a) Marital status, MR/UM are 282/62 (pretest) and 278/73 (posttest); (b) Gender, "ME/FM are 142/199 (pretest) and 229/116 (posttest); (c) Age, MD/YU are 100/81 (pretest) and 98/110 (posttest); (d) Ethnicity, MJ/MN are 316/28(pretest) and 325/26 (posttest); (e) Educational attainment, HE/LE are 113/153 (pretest) and 151/113 (posttest); (f) Income level, HI/LIare 175/109 (pretest) and 165/121 (posttest).

\subsubsection{Common Method Variance}

In order to overcome the problem of method bias, Common Method Variance (CMV) was controlled with procedural remedy method and statistical method(Podsakoff, MacKenzie, Lee, \& Podsakoff, 2003).First, the procedural remedy was implemented through three procedures: (a) dividing the questionnaire survey into two stages; (b) collecting data from four types of communities; (c) using anonymous questionnaire.

Second, the statistical control was implemented with Harman's single-factor test. The basic assumption of this method is that "if CMV was substantial, one general factor would account for the majority of the whole information ( $>50 \%)$ " (Podsakoff, MacKenzie, \& Podsakoff, 2012). Factor Analysis was implemented with SPSS 20.0 software to check the parameter of " $\%$ of variance", and the results show that: its value is 22.226 for the pretest data, 25.405 for the posttest data, which means that the CMV of survey was acceptable.

\subsubsection{Non-parametric test}

In view of the problem of sampling consistency, non-parametric test was implemented(Hollander, Wolfe, \& Chicken, 2013). The parameter of Kolmogorov-Smirnov was used to compare the characteristics of demographic groups regarding the two-stage survey. The results are as follows: Gender $($ Sig. $=0.220, \quad \mathrm{R}), \quad$ Age $\quad($ Sig. $=0.439, \quad \mathrm{R}), \quad$ Ethnicity (Sig.=1.000, R), Education (Sig. $=0.131$, R), Income (Sig. $=0.997$, R). Symbol "R" represents "retains", which means there is no significant variance between two-stage surveys.

\subsubsection{Exploratory Factor Analysis}

Creating good measures involves both writing good questions and organizing them to form the questionnaire (USSR,n.d). Because of this, more items were designed to measure the variables, which should be refined when the data have been collected. Explore Factor Analysis (EFA) was implemented based on SPSS 20.0, and then the items in the questionnaire were processed according to two rules (Fabrigar, 1999): first, item loading should approach 0.5 (Hair, Black, Babin, Anderson, 2009) unless there are not enough items; second, no more than four items should be selected for each variable taking into account the balance between variables. At last, a total of 29 measuring items were left, in which 11 items was used to measure three social context variables, 12 items was used to measure three predecisional variables, and 6 items was used to measure six demographic variables.

\section{Results}

\subsection{Interactions between social context variables}

In order to discuss the interactions between social context variables, sixteen competing models were designed with the combinations of "FKN, FFC, and MC". Structural Equation Modeling (SEM) was used to rank the competing models with four criteria: first, the model should be convergent; second, lower ECVI is better fit (Cudeck, 1989); third, one with the smallest AIC would be chosen (Kieseppä, 2003); fourth, the model is better if it can comprise the characteristics of rival models (Mizon,1984).

SEM model was built and run based on AMOS 20.0 software, and then the results were obtained. Table 2 represents the combinations and corresponding parameters. 
Table 2.Combinations of social context variables and corresponding parameters

\begin{tabular}{|c|c|c|c|c|c|c|c|}
\hline \multirow{2}{*}{ Model } & \multirow{2}{*}{ Combinations } & \multicolumn{2}{|c|}{ Cvg. } & \multicolumn{2}{|c|}{$E V C I$} & \multicolumn{2}{|c|}{$A I C$} \\
\hline & & Pre & Post & Pre & Post & Pre & Post \\
\hline Model 1 & $M C \leftarrow F K N, F F C \leftarrow F K N$ & $\mathrm{~N}$ & $\mathrm{~N}$ & 1.96 & 2.01 & 673.77 & 703.51 \\
\hline Model 2 & $M C \leftarrow F K N, F F C \leftarrow F K, F F C \leftarrow M C$ & Y & $\mathrm{N}$ & 1.93 & 2.03 & 660.66 & 710.08 \\
\hline Model 3 & $M C \leftarrow F K N, F F C \leftarrow F K N, M C \leftarrow F F C$ & $\mathrm{Y}$ & $\mathrm{N}$ & 1.93 & -- & 660.66 & -- \\
\hline Model 4 & $\begin{array}{l}M C \leftarrow F K N, \quad F F C \leftarrow F K, \quad F F C \leftarrow M C, \\
M C \leftarrow F F C\end{array}$ & $\mathrm{~N}$ & $\mathrm{~N}$ & -- & -- & -- & -- \\
\hline Model 5 & $M C \leftarrow F K N$ & $\mathrm{~N}$ & $\mathrm{~N}$ & 1.96 & 2.01 & 671.86 & 712.97 \\
\hline Model 6 & $M C \leftarrow F K N, F F C \leftarrow M C$ & Y & $\mathrm{N}$ & 1.93 & 2.01 & 661.07 & 711.91 \\
\hline Model 7 & $M C \leftarrow F K N, M C \leftarrow F F C$ & Y & $\mathrm{N}$ & 1.93 & -- & 660.66 & -- \\
\hline Model 8 & $M C \leftarrow F K N, F F C \leftarrow M C, M C \leftarrow F F C$ & Y & $\mathrm{N}$ & 1.93 & 2.03 & 660.66 & 710.08 \\
\hline Model 9 & $F F C \leftarrow F K N$ & $\mathrm{~N}$ & Y & 1.97 & 2.00 & 675.97 & 701.22 \\
\hline Model 10 & $F F C \leftarrow F K N, F F C \leftarrow M C$ & Y & $\mathrm{N}$ & 1.93 & -- & 660.66 & -- \\
\hline Model 11 & $F F C \leftarrow F K N, M C \leftarrow F F C$ & Y & Y & 1.93 & 2.01 & 660.91 & 704.16 \\
\hline Model 12 & $F F C \leftarrow F K N, F F C \leftarrow M C, M C \leftarrow F F C$ & $\mathrm{Y}$ & $\mathrm{N}$ & 1.93 & 2.00 & 660.66 & 700.82 \\
\hline Model 13 & Null & Y & $\mathrm{N}$ & 1.93 & -- & 660.66 & -- \\
\hline Model 14 & $F F C \leftarrow M C$ & $\mathrm{~N}$ & $\mathrm{~N}$ & 1.93 & 2.01 & 661.07 & 702.79 \\
\hline Model 15 & $M C \leftarrow F F C$ & Y & $\mathrm{Y}$ & 1.93 & 2.01 & 660.91 & 704.16 \\
\hline Model 16 & $F F C \leftarrow M C, M C \leftarrow F F C$ & $\mathrm{~N}$ & $\mathrm{~N}$ & -- & -- & -- & -- \\
\hline
\end{tabular}

Note: "૯" means the influence from the latter variable to the former variable; "-." represents "no influence"; Y represents "convergent"; N represents "no convergent"; Cvg. represents "convergence status".

It can be seen from the Table 2 that: first, only Model 11 and Model 15 were valid regarding the convergence rule; second, the values of EVCI, AIC, and BIC are the same between Model 11 and Model 15; third, Model 11 is better than Model 15 taking into account the encompass principle.

Depending on the structure of Model 11, the interactions between social context variables can be found, which was presented as "MC $\leftarrow$ FFC $\leftarrow$ FKN". It can be seen that immersing in friend and kinship network is useful to face-to-face communication; participating in face-to-face communication is beneficial to media communication.

\subsection{Effects of social context on predecisional processes}

In order to analyze hypothesis paths, SEM was built according to Model 11 and above hypothesis paths (section 2.2.1) with AMOS 20.0 software. The results were checked with five criteria: C.R. should be greater than 1.96 (Hanneman, Kposowa, \& Riddle, 2013); P-value should be less than 0.05 (Nuzzo, 2014); S.E. should be positive; the bigger the value of unstandardized and standardized regression coefficients, the stronger the hypothesis (Hargens, 1976).

The results of nine hypothesis paths are represented in Table 3, in which the result cannot be accepted unless the pretest result and posttest result are significant simultaneously. 
Table 3. The testing parameters of hypothesis paths

\begin{tabular}{|c|c|c|c|c|c|c|c|c|c|c|}
\hline \multirow{2}{*}{ Hypothesis } & \multicolumn{2}{|c|}{ UnStd. } & \multicolumn{2}{|c|}{ S.E. } & \multicolumn{2}{|c|}{ C.R. } & \multicolumn{2}{|c|}{$P$} & \multicolumn{2}{|c|}{ Std. } \\
\hline & Pre- & Post- & Pre- & Post- & Pre- & Post- & Pre- & Post- & Pre- & Post- \\
\hline$H_{1 a}: R P \leftarrow M C$ & 0.59 & 0.83 & 0.12 & 0.15 & 5.07 & 5.62 & $* * *$ & $* * *$ & 0.57 & 0.51 \\
\hline$H_{l b}: A T \leftarrow M C$ & -0.03 & 0.15 & 0.08 & 0.08 & -0.46 & 1.87 & 0.65 & 0.06 & -0.05 & 0.14 \\
\hline$H_{l c}: C P \leftarrow M C$ & -0.01 & -0.14 & 0.11 & 0.09 & -0.10 & -1.62 & 0.92 & 0.11 & -0.01 & -0.36 \\
\hline$H_{2 a}: R P \leftarrow F F C$ & -0.14 & -0.02 & 0.10 & 0.11 & -1.48 & -0.15 & 0.14 & 0.89 & -0.16 & -0.01 \\
\hline$H_{2 b}: A T \leftarrow F F C$ & 0.24 & 0.38 & 0.07 & 0.07 & 3.58 & 5.64 & $* * *$ & $* * *$ & 0.40 & 0.42 \\
\hline$H_{2 c}: C P \leftarrow F F C$ & -0.05 & 0.09 & 0.10 & 0.07 & -0.49 & 1.40 & 0.63 & 0.16 & -0.07 & 0.28 \\
\hline$H_{3 a}: R P \leftarrow F K N$ & 0.05 & -0.65 & 0.08 & 0.38 & 0.56 & -1.70 & 0.58 & 0.09 & 0.04 & -0.17 \\
\hline$H_{3 b}: A T \leftarrow F K N$ & 0.00 & 0.06 & 0.05 & 0.10 & 0.09 & 0.57 & 0.93 & 0.57 & 0.01 & 0.02 \\
\hline$H_{3 c}: C P \leftarrow F K N$ & 0.37 & -0.07 & 0.14 & 0.09 & 2.69 & -0.84 & 0.01 & 0.40 & 0.42 & -0.08 \\
\hline
\end{tabular}

Note: “***" means the value which is less than $0.001 ;$ "६" have the same meaning with Table

2.;UnStd.represents"unstandardized regression weights"; Std. represents "standardized regression weights".

The results show that: First, in light of consistency of two-stage data, two hypothesis paths of "RP $\leftarrow$ MC (C.R.: 5.07/5.62) and AT FFC" (C.R.: 3.58/5.64) are significant. Second, in light of the value of unstandardized regression weights and standardized regression weights, the influence of MC (UnSd.: 0.59/0.83; Sd.: 0.57/0.51) is stronger than FFC (UnSd.: 0.24/0.38; Sd.: 0.40/0.42). Third, FKN is negative because there is no significant hypothesis path related to it.

\subsection{Variance across demographic groups}

In order to discuss the variance of significant paths across demographic groups, Multiple Group Analysis(MGA) was implemented. SEM models of path "RP $\leftarrow$ MC" and path "AT $\leftarrow$ FFC" were built separately.

We run SEM model based on AMOS 20.0 software, and then check the following parameters: First, model fit parameter was checked to make sure that the model selected achieves the minimum value. Second, "ECVI" and "AIC was checked to rank the model, lower ECVIor AICis better fit (Cudeck, 1989). Third, significant level was checked with pairwise parameter of specific path $(>1.64)$. If pairwise parameter was not reported, unstandardized and standardized regression coefficients $(>0.4)$ would be checked as an alternative (Richards, 1982). The final results were represented in Table 4, which represent the variance of two paths across demographic groups.

The results are summarized from two aspects: First

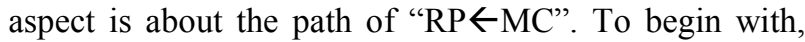
we checked the pretest data with the parameter of P.P $(>2.20)$, and the posttest data with parameters of UnStd. and Std. $(>0.4)$, and then found that there are variances across education attainment groups. Furthermore, we checked the pretest data and the posttest data with parameters of UnStd. and Std. $(>0.4)$, and found that there are variances across gender groups.

Second aspect is about the path of "AT $\leftarrow$ FFC". We checked the pretest data and the posttest data with parameters of UnStd. and Std. (>0.4), and found that there are variances across education attainment groups, as well as variances across income level groups. 
Table 4.MGA parameters of two paths across demographic groups

\begin{tabular}{|c|c|c|c|c|c|c|c|c|}
\hline \multirow{2}{*}{\multicolumn{3}{|c|}{ Demographic variables }} & \multicolumn{3}{|c|}{$R P \leftarrow M C$} & \multicolumn{3}{|c|}{$A T \leftarrow F F C$} \\
\hline & & & \multirow{2}{*}{$\begin{array}{l}\boldsymbol{P . P .} . \\
-0.07\end{array}$} & \multirow{2}{*}{$\begin{array}{l}\text { UnStd. } \\
0.38\end{array}$} & \multirow{2}{*}{$\frac{\text { Std. }}{}$} & \multirow{2}{*}{$\begin{array}{l}\boldsymbol{P . P .} \\
0.96\end{array}$} & \multirow{2}{*}{$\begin{array}{l}\text { UnStd. } \\
0.78\end{array}$} & \multirow{2}{*}{$\begin{array}{c}\text { Std. } \\
0.51\end{array}$} \\
\hline Age & Pre- & $E D$ & & & & & & \\
\hline & & $Y U$ & -0.07 & 0.38 & 0.49 & 0.96 & 1.02 & 0.58 \\
\hline & Post- & $E D$ & -0.85 & 0.69 & 0.40 & 3.53 & 0.36 & 0.67 \\
\hline & & $Y U$ & -0.85 & 0.49 & 0.46 & 3.53 & 0.83 & 0.76 \\
\hline \multirow[t]{4}{*}{ Education } & Pre- & $H E$ & 2.20 & 0.29 & 0.42 & -- & 0.83 & 0.53 \\
\hline & & $L E$ & 2.20 & 0.62 & 0.44 & -- & 0.83 & 0.53 \\
\hline & Post- & $H E$ & -- & 0.55 & 0.49 & -- & 0.55 & 0.71 \\
\hline & & $L E$ & -- & 0.55 & 0.52 & -- & 0.55 & 0.69 \\
\hline \multirow[t]{4}{*}{ Gender } & Pre- & $M E$ & -- & 0.49 & 0.37 & -- & 0.77 & 0.41 \\
\hline & & $F M$ & -- & 0.49 & 0.49 & -- & 0.77 & 0.51 \\
\hline & Post- & $M E$ & -- & 0.76 & 0.51 & 0.27 & 0.58 & 0.63 \\
\hline & & $F M$ & -- & 0.76 & 0.51 & 0.27 & 0.61 & 0.70 \\
\hline \multirow[t]{4}{*}{ Income } & Pre- & $H I$ & -2.83 & 0.72 & 0.50 & -- & 0.69 & 0.37 \\
\hline & & $L I$ & -2.83 & 0.31 & 0.30 & -- & 0.69 & 0.48 \\
\hline & Post- & $H I$ & -0.39 & 0.76 & 0.46 & -- & 0.55 & 0.71 \\
\hline & & $L I$ & -0.39 & 0.68 & 0.43 & -- & 0.55 & 0.69 \\
\hline
\end{tabular}

Note: P.P.represents "Pairwise Parameter"; UnStd. And Std. have the same meaning with Table 3.; “--" represents "no report".

\section{Discussion}

The findings from this research suggest that: the social context can influence predecisional processes in two ways, which are "RP $\leftarrow$ MC" and "AT $\leftarrow$ FFC"; furthermore, the order of influence strength is "MC $>$ FFC $>$ FKN"; at last, there are interactions between social context variables, which is "FKN $\rightarrow$ FFC $\rightarrow$ MC". The detailed explanations are as follows.

On the one hand, the media communication does influence individual reception of risk information. Each medium has its own technological capabilities that influence the delivery of text, sound, and visual images (Croteau, Hoynes,\& Milan, 2011, pp.285-286), so it is natural that the access to different media depends on individual habits and lifestyle. Furthermore, the findings show education attainment and age can influence media communication significantly, which might be explained by the theory that education can develop habits, skills, and abilities (Mirowsky, 1998), as well as the theory that age can engender different circadian rhythmicity (Minors, Atkinson, Bent, Rabbitt, \& Waterhouse, 1998).In addition, the impact of media communication is the strongest among three social context variables, which shows that media channel should be emphasized because of its capacity to cover extensive population. Thus, it can be deduced that media channel should be diverse with respect to the different groups, such as elder/youth groups and blue-collar/white-collar groups, in order to increase individual reception of risk information, which should be helpful for expanding the coverage of risk communication.

On the other hand, the face-to-face communication does influence individual attention to risk information. Humans are driven to protect against external threats (Lawrence, Nohria, 2002), so they are easy to be impressed by the vivid on-site activities. Furthermore, the findings show that education attainment and income level can influence face-to-face communication significantly. It is well-known that socioeconomic status is related to participation in physical activity. Therefore, the social status might become "perceived barriers" (Cerin\& Leslie, 2007) to impede face-to-face activity. In addition, the findings also show that face-to-face communication can influence media communication. Thus, it can be deduced that physical activities should be specific with respect to the different socioeconomic 
groups, such as the middle class and the lower class, in order to enhance individual attention to risk information, which should be helpful for improving the effectiveness of risk communication.

Surprisingly, friend and kinship network does not influence any predecisional processes variables, but it influences face-to-face communication activity. The former finding might be explained by Lindell and Perry (2004, p.139)'s theory that available response time impede individual decision behavior in the long-term hazard adjustment. The latter finding has ever been interpreted by many researchers (such as Voorhees, et.al., 2005; Nauert, 2012), whose theories showed that social networks can influence physical activity in a positive or negative way. Thus, it can be seen that social influence should be emphasized, such as the power of kids and elder, in order to motivate public participation towards communication activities.

Quite surprisingly, no social context variable does exert significant influence on individual comprehension of risk information. The terminology of risk information is usually hard to be understood by the local communities (Pearson, 2012). Therefore, there might be some mismatch between the information people receive and what they understand(HHS, 2010). The findings demonstrate that there are big challenges in the comprehension of risk information concerning the residents in Beijing. Thus, it can be seen that the problem of translating scientific jargon into plain language should be emphasized in order to improve public comprehension of risk information.

Overall, this research suggests that the social context can influence predecisional processes through media communication and face-to-face communication, but the methods should be diverse and specific. In addition, the topic of social conformity, as well as the problem of translating terminology into plain language should be emphasized.

\section{Conclusions}

It can be found that media communication, face-to-face communication and friend and kinship network play different role in the link between social context and predecisional processes. They should be designed diversely and specifically concerning the characteristics of different demographic groups. It should be emphasized that there are big problem related to public comprehension of social transmitted information. In the future, the research should cover the particular social context regarding demographic characteristics, the facilitating and barriers in the social context, and the role of social conformity.

\section{Acknowledgements}

With the sponsor of China Scholarship Council (201306035027) this paper was completed at the Disaster Research Center of University of Delaware. I would like to thank Dr. James Kendra for his recommendation of corresponding literature, as well as Dr. Sarah DeYoung for her help in the field of social psychology. Meanwhile, I would like to express my gratitude to Mrs. Xao Han of Beijing Municipal Office of Civil air defense and $\mathrm{Mr}$. Zhen $\mathrm{Xu}$ of the Haidian District government for their help in the survey.

\section{Reference}

BMBS, Beijing Municipal Bureau of Statistics. (2014, June 18). Data interpretation of permanent residents of Beijing in 2013. Retrieved from http://www.bjstats.gov.cn/sjfb/bssj/ndsj/ndsjfpfb/2013n/20 1406/t20140618_274951.htm (in Chinese)

Bodner,G., Klobuchar,M., \&Geelan,D. (2001). The many forms of constructivism. Journal of Chemical Education, 78, 1107-1134.

Bouza-Herrera,C.N. (2010). Handling missing data in ranked set sampling. New York, NY: Springer, 2010. doi: 10.1007/978-3-642-39899-5

Byrne,B.M. (2001). Structural equation modeling with AMOS: basic concepts, applications, and programming. Mahwah, NJ: Lawrence Erlbaum Associates.

Cerin,E., \& Leslie, E. (2007, February). Socio- Economic status and perceived barriers to physical activity.Presentation at the 2007 Active Living Research Annual Conference. Retrieved from http://activelivingresearch.org/socio-economic-status-and-p erceived-barriers-physical-activity

Cochran,W.G.(1977). Sampling Techniques (3rd Edition). Wilmington, Wiley.

Croteau,D., Hoynes,W., Milan,S. (2011). Media society: Industries, images, and audiences. Los Angels, SAGE.

CSCB, Community Service Center of Beijing. (2015, May 16). Community construction. Retrieved from http://hd.bjcs.gov.cn/wps/portal/template1/bjssq

Cudeck,M.R. (1989). Single sample cross-validation indices for covariance structures. Multivariate Behavioral Research, 24(4): 445-455.

Enarson,E., Fothergill,A., \&Peek,L. (2007). Gender and disaster: Foundations and directions. (pp. 130-146). In Rodríguez,H., Quarantelli,E.L., Dynes,R.R. (Eds.). Handbook of Disaster Research, Springer.

Fabrigar,L.R., Wegener,D.T., MacCallum,R.C., \&Strahan,E.J. (1999). Evaluating the use of exploratory factor analysis in psychological research. Psychological Methods, 4(3), 272-299.

Fiske,S.T., \&Taylor,S.E.(1991). Social cognition (2nd Edition). New York: McGraw-Hill. 
Gaillard, JC.(2012). Case, ethnicity, religious affiliation and disaster. (pp. 459-469). In B.Wisner, J.C Gaillard, \&I.Kelman.The Routledge handbook of harzards and disaster risk reduction. London, Routledge.

Hair,J.F., Black,W.C., Babin,B.J., \&Anderson,R.E. (2009). Multivariate data analysis (7th Edition). Upper Saddle River, NJ: Prentice Hall, 2009.

Hanneman,R.A., Kposowa,A.J., \&Riddle,M.D. (2013). Basic statistics for social research. Wilmington, DE: Jossey-Bass.

Hargens,L.L. (1976). A note on standardized coefficients as structural parameters. Sociological Methods and Research, $5,247-256$.

Hayden,J (Ed.). (2009). Introduction to health behavior theory.Boston, Jones and Bartlet Publishers.

Health,.L., \&O'Hair,H.D.(Eds.).(2009). Handbook of risk and crisis communication.New York, NY, Routledge.

HHS, U.S. Department of Health and Human Services, Office of Disease Prevention and Health Promotion. (2010). Plain language: A promising strategy for clearly communicating health information and improving health literacy. Healthy People 2010 Health Communication Focus Area. Retrieved from http://health.gov/communication/literacy/plainlanguage/Pla inLanguage.htm

Hollander,M., Wolfe,D.A., \&Chicken,E. (2013). Nonparametric statistical methods. Hoboken, NJ: Wiley.

Kieseppä,I.A. (2003). AIC and large samples. Philosophy of Science, 70(5): 1265-1276.

Lasswell,H.D. (1948). The structure and function of communication in society.In L. Bryson (Ed.). The Communication of Ideas: A series of addresses (p. 117). New York, NY: Institute for Religious and Social Studies.

Lawrence,P.R., Nohria,N. (2002). Driven: How Human Nature Shapes Our Choices.San Francisco, CA, Jossey-Bass.

Lazarus,R.S., \&Folkman,S. (1984). Stress, appraisal, and coping. New York: Springer.

Lindell,M.K., Perry, R.W. (2012). The protective action decision model: Theoretical modifications and additional evidence. Risk Analysis, 32(4), 616-632.

Lindell,M.K., \&Perry,R.W. (2004). Communicating environmental risk in multiethnic communities. Los Angeles: Sage Publications.

Maskrey A. (1989). Disaster mitigation: A community-based approach. Oxford, Oxfam.

Minors D., Atkinson G., Bent N., Rabbitt P., \& Waterhouse J., (1998). The effects of age upon some aspects of lifestyle and implications for studies on circadian rhythmicity. Age Ageing, 27(1):67-72.

Mirowsky,J. (1998). Education, personal control, lifestyle and health: A human capital hypothesis. Research on Aging, 20(4), 415-449. doi: 10.1177/0164027598204003

Mizon,G.E. (1984). The encompassing approach in econometrics. Canberra: Australian National University, Faculty of Economics and Research School of Social Sciences.

Nauert,R. (2012, September 11). Does Social Networking Limit Physical Activity? Retrieved from http://psychcentral.com/news/2012/09/11/does-social-netw orking-limit-physical-activity/44412.html

Nuzzo,R. (2014). Scientific method: Statistical errors. Nature, 506: $150-152$.

Pearson,L. (2012, November, 11). Early warning of disasters: Facts and figures. SciDev Net. Retrieved from

$\mathrm{http}: / /$ www.scidev.net/global/communication/feature/earlywarning-of-disasters-facts-and-figures-1.html

Petty,R., \&Cacioppo,J. (1986). The elaboration likelihood model of persuasion. In L. Berkowitz (Ed.), Advances in experimental social psychology (pp.123-205).New York: Academic Press.

Podsakoff,P.M., MacKenzie,S.B., \&Podsakoff,N.P. (2012). Sources of method bias in social science research and recommendations on how to control it. Annual Review of Psychology, 63, 539-569. doi: 10.1146/annurev-psych-120710-100452

Podsakoff,P.M., MacKenzie,S.B., Lee,J., \& Podsakoff, N. P. (2003). Common method biases in behavioral research: A critical review of the literature and recommended remedies. Journal of Applied Psychology, 88(5), 879-903.

Richards,J.M. (1982). Standardized versus unstandardized regression weights.Applied Psychological Measurement, 6, 201-212.

Shannon,C.E. (1948). A mathematical theory of communication. The Bell System Technical Journal, 27, 379-423.

Smith,S.M. (2013, April 8). Determining sample size: How to ensure you get the correct sample size. Retrieved from https://www.qualtrics.com/blog/determining-sample-size/

Terpstra,T., Lindell,M.K. (2012). Citizens' perceptions of flood hazard adjustments: An application of the protective action decision model. Environment and Behavior, 45(8), 993-1018.

USSR, U.S. Survey Research. (n.d.).Questionnaire design. Retrieved from

http://www.pewresearch.org/methodology/u-s-survey-resea $\mathrm{rch} /$ questionnaire-design/

Voorhees.C.C., Murray,D., Welk,G., Birnbaum,A., Ribisl,K.M., Johnson,C.C., Pfeiffer,K.A., Saksvig,B., \&Jobe,J.B. (2005). The role of peer social network factors and physical activity in adolescent girls. American Journal of Health Behavior, 29(2), 183-190.

Wang,F. (2014). Modeling public s protective behavior response from the perspective of risk perception .Dissertation, University of Science and Technology of China. (inChinese)

Wirth L.(1938). Urbanism as a way of life. American Journal of Sociology, 189-197.

Zhang,Y.X. (2006). Community, urbansim and social networks: Research about social ties in urban. Social Sciences in Guangdong, 5, 183-188. doi: 10.3969/j.issn.1000-114X.2006.05.029 (in Chinese)

Zhu Y. (2014, September 23). China's nuclear expansion threatened by public unease. China dialogue. Retrieved from

https://www.chinadialogue.net/article/show/single/en/7336 -Chinese-protesters-threaten-nuclear-expansion (in Chinese) 